\title{
Reducing seabird bycatch in the Hawaii longline tuna fishery
}

\author{
Eric Gilman ${ }^{1,2, *}$, Donald Kobayashi ${ }^{3,4}$, Milani Chaloupka ${ }^{5}$ \\ ${ }^{1}$ IUCN Global Marine Programme, 2718 Napuaa Place, Honolulu, Hawaii 96822, USA \\ ${ }^{2}$ Centre for Ecology and Conservation, University of Exeter, Cornwall Campus, Penryn TR10 9EZ, UK \\ ${ }^{3}$ US NOAA Fisheries, Pacific Islands Fisheries Science Center, 2570 Dole Street, Honolulu, Hawaii 96822, USA \\ ${ }^{4}$ Department of Environmental Sciences, University of Technology, Sydney, New South Wales 2007, Australia \\ ${ }^{5}$ Ecological Modeling Services, PO Box 6150, University of Queensland, St. Lucia, Queensland 4067, Australia
}

\begin{abstract}
Mortality in longline fisheries represents a global threat to some species of pelagic seabirds. Regulations were adopted in 2001 to reduce seabird bycatch in the Hawaii longline tuna fishery. We used a Poisson generalized additive regression modeling approach to evaluate the change in seabird bycatch rates from the pre- to post-regulation period, and to evaluate the efficacy of alternative combinations of seabird bycatch reduction methods employed during the post-regulation period. Informative covariates of temporal and geo-referenced spatial effects of fishing effort and sampling variation commonly found with count data were included in the model to provide a better inference of the effect of employing required changes in fishing gear and methods. We found a significant $67 \%$ (95\% CI: 62 to 72 ) reduction in the seabird bycatch rate following the introduction of regulations. Post-regulation, sets employing 4 different combinations of seabird avoidance methods all resulted in significant reductions to the pre-regulation seabird catch rate. Employing side-setting and $60 \mathrm{~g}$ weights was the only combination with no seabird captures during the post-regulation period. Using heavier branch line weights and treated bait (thawed and dyed blue) both significantly reduced seabird catch rates. Temporal and spatial distribution of fishing effort and the timing of initiating setting were also significant factors affecting seabird bycatch rates: time-area closures and restricting the timing of setting could further reduce seabird bycatch. A substantial proportion of seabird captures occurred south of the area where mitigation measures are required: moving the southern boundary farther south would further reduce seabird catches.
\end{abstract}

KEY WORDS: Albatross · Bycatch $\cdot$ Fisheries $\cdot$ Longline $\cdot$ Mitigation $\cdot$ Seabird Resale or republication not permitted without written consent of the publisher

\section{INTRODUCTION}

Mortality in longline fisheries is the most critical global threat to most species of albatrosses and large petrels (Gales 1998, Brothers et al. 1999, Gilman et al. 2005). Primarily while fishing gear is being set, seabirds are hooked or entangled, dragged underwater, and drown as the gear sinks. The species of seabirds most frequently caught on longlines are albatrosses and petrels in the Southern Ocean, Arctic fulmar Fulmarus glacialis in North Atlantic fisheries and albatrosses, gulls, and fulmars in North Pacific fisheries (Brothers et al. 1999). Longlining occurs through- out the world's oceans, has been used since the 19th century, and is practised by small-scale domestic artisanal fisheries with small, open vessels to modern mechanized industrialized fleets from distant-water fishing nations with large vessels. Pelagic longlines, where gear is suspended from a mainline drifting freely in the pelagic environment, at depths anywhere from the sea surface to $400 \mathrm{~m}$, mainly target large tunas Thunnus spp., swordfish Xiphias gladius, other billfishes Istiophoridae spp., dolphin fish (mahimahi) Coryphaena spp. and sharks. Longlines can be up to $100 \mathrm{~km}$ long and carry up to 3500 baited hooks (Beverly et al. 2003, Gilman et al. 2008). Incidental bycatch 
of Laysan Phoebastria immutabilis and black-footed $P$. nigripes albatrosses in North Pacific longline fisheries, including the Hawaii pelagic longline tuna and swordfish fisheries, is a conservation and management concern (Cousins \& Cooper 2000, US Fish and Wildlife Service 2002, 2004, Gilman \& Freifeld 2003, Lewison \& Crowder 2003, Niel \& Lebreton 2005).

In 2007 there were 129 active domestic Honolulubased pelagic longline vessels targeting tuna, setting 38.8 million hooks (Gilman 2008, Gilman et al. 2008, US National Marine Fisheries Service 2008). The observer coverage rate of the fishery was about $4 \%$ from 1994 to 2000, after which it was increased to about $20 \%$. The longline tuna fishery lands primarily bigeye Thunnus obesus, yellowfin T. albacares and albacore $T$. alalunga tunas as well as several incidental pelagic species. The fishery annually lands about $9800 \mathrm{t}$ of fish worth USD 43 million (Gilman 2008). Vessels are 10 to $31 \mathrm{~m}$ long. The tuna fishery operates year-round. Vessels make trips of about $21 \mathrm{~d}$ duration, and about 15 trips per year, with about 10 sets per trip and 2000 hooks per set. Fishing grounds are in the western and central Pacific Ocean, within the Exclusive Economic Zone adjacent to Hawaii and on the high seas. From January through March, effort is concentrated between 15 and $35^{\circ} \mathrm{N}$ latitude and 150 and $180^{\circ} \mathrm{W}$ longitude. From April through June fishing expands to the south and spreads farther east and west to about $145^{\circ} \mathrm{W}$ and $170^{\circ} \mathrm{E}$. Baited hooks are set at depths between 35 and $224 \mathrm{~m}$. Vessels use a wire trace, place a lead-centered swivel of 45 to $80 \mathrm{~g}$ within $1 \mathrm{~m}$ of the hook, use fish for bait (a mix of frozen mackerel, saury and sardine) and do not use lightsticks. The gear soaks during the day and is hauled at night. Mainline ${ }^{1}$ length is about $50 \mathrm{~km}$ and is deployed with a hydraulic shooter. The primary hook used is a tuna 3.6 ring hook, with some use of 14/0,15/0 and 16/0 circle hooks (Gilman et al. 2008). This is a general description of the gear and operational characteristics of the Hawaii longline tuna fleet; however, there may be large variability in fishing gear and methods between vessels in the fleet and even for an individual vessel.

Based on results from controlled and comparative experiments of seabird avoidance methods in the Hawaii longline fleet (McNamara et al. 1999, Boggs 2001, Gilman et al. 2007a), fishery management

${ }^{1}$ The mainline is monofilament line that is deployed horizontally off a reel, onto which branch lines with baited hooks, buoys, and radio beacons are attached. A branch line is the line that attaches to the mainline with a clip, is generally 6 to $10 \mathrm{~m}$ in length in this fishery, and has the following components: clip attached to the mainline, 6 to $10 \mathrm{~m}$ of monofilament nylon line, 45 or $60 \mathrm{~g}$ lead center swivel, wire leader, and a baited hook authorities adopted and amended regulatory measures for the Hawaii longline fleet to reduce seabird catch rates. Since regulations were first adopted in June 2001, total seabird captures in the combined Hawaii longline tuna and swordfish fisheries dropped $96 \%$ from an estimated 2433 in 2000 to 88 in 2006 (Van Fossen 2007). Current regulations, which came into effect on 18 January 2006, require Hawaii longline vessels targeting tuna, when fishing north of $23^{\circ} \mathrm{N}$, to either:

(1) Side-set, attach weights that are a minimum of $45 \mathrm{~g}$ to branch lines within $1 \mathrm{~m}$ of the hook, and deploy a bird curtain aft of a mainline shooter. The mainline must be deployed a minimum of $1 \mathrm{~m}$ forward from the stern. The bird curtain must be a minimum of $3 \mathrm{~m}$ long with 3 or more streamers; or,

(2) Attach weights that are a minimum of $45 \mathrm{~g}$ to branch lines within $1 \mathrm{~m}$ of the hook; when seabirds are present, discharge fish, offal (fish parts) or spent bait while setting or hauling from the opposite side of the vessel from where gear is being set or hauled; and use only completely thawed, blue-dyed bait to match a color quality control card (US National Marine Fisheries Service 2005).

Side-setting means setting longline gear from the side of the vessel rather than the conventional position at the stern (Fig. 1). When implemented to prescription, crew throw baited hooks forward and close to the side of the vessel hull where seabirds, such as albatrosses, are unable or unwilling to pursue them. Ideally, by the time the stern passes, the hook has sunk beyond the reach of seabirds (Gilman et al. 2007a). Employment of a bird curtain in combination with

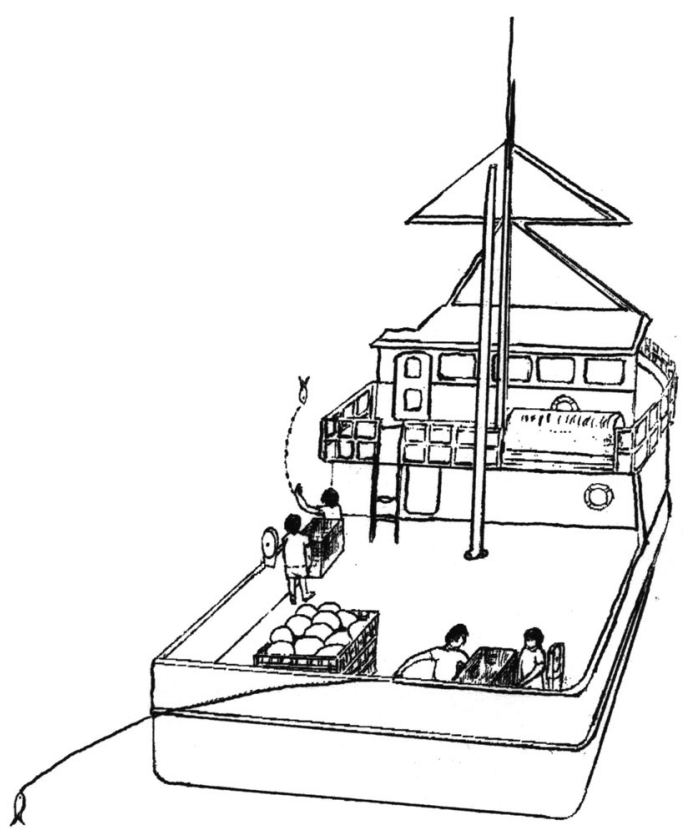

Fig. 1. Deck positions for side- versus stern-setting on longline fishing vessels (illustration courtesy of Nigel Brothers) 
side-setting is believed to further reduce seabird access to baited hooks being set by preventing foraging seabirds from manoeuvering close to the vessel hull near where the setting operation is taking place (Gilman et al. 2007a). Adding weights to branch lines increases the baited hook sink rate, reducing the risk of seabirds being able to access baited hooks as they are being set (Brothers et al. 1999, Boggs 2001). The intent of dyeing bait dark blue, by reducing the contrast between the bait and sea color, is to make it more difficult for birds to detect the bait when foraging from above (McNamara et al. 1999, Boggs 2001, Minami \& Kiyota 2002, Gilman et al. 2005, 2007a). To dye bait blue to achieve regulatory-required darkness, bait is supposed to be completely thawed and soaked in a tub with dissolved blue food coloring (Virginia Dare FD\&C Blue No. 1) powder at a concentration of $4 \mathrm{~g} \mathrm{l}^{-1}$ of water for 1 to $4 \mathrm{~h}$ (Fig. 2).

A comparative study of the efficacy of side-setting, blue-dyed bait and other seabird avoidance methods found that side-setting resulted in a significantly lower seabird catch rate than blue-dyed bait, and that sidesetting provided substantial operational benefits (Gilman et al. 2007a). Other seabird avoidance methods were found to be relatively impractical for employment by crew (Gilman et al. 2007a). Although Gilman et al. (2007a) tested the comparative single factor efficacy of 3 types of seabird avoidance methods, this study used observer data to compare the efficacy of different combinations of seabird avoidance strategies employed by the fleet during conventional commercial fishing operations.

We analyzed observer data from the US National Marine Fisheries Service for the Hawaii longline tuna fishery to calculate and compare seabird bycatch rates for pre- and post-regulation periods requiring the

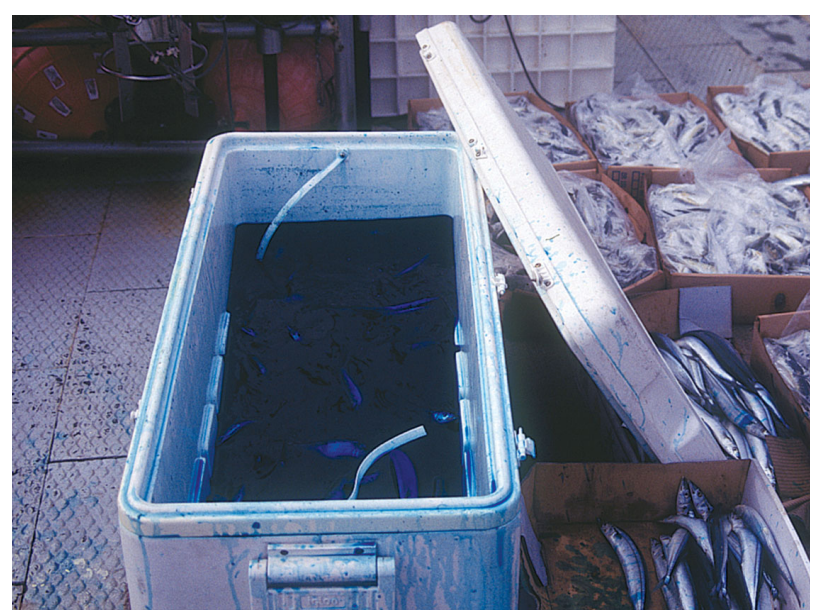

Fig. 2. Bait is completely thawed and dyed blue by soaking in a large tub with dissolved blue food coloring to achieve regulatory-required darkness employment of seabird avoidance methods, and different combinations of methods employed to avoid catching seabirds during the post-regulation period.

\section{METHODS}

Pre- vs. post-regulation period. To compare pre- vs. post-regulation seabird capture rates, we analyzed data from the Hawaii longline observer program for Hawaii-based longline tuna-targeting sets (defined by the US National Marine Fisheries Service [2005] as sets containing $\geq 15$ hooks between floats) for the periods before and after seabird avoidance regulations came into effect. The analysis was conducted employing only sets where one or more albatross was observed present during setting or hauling operations and/or a seabird was captured. For sets where no albatrosses were present, the observation that no albatrosses were captured is a result of an absence of albatrosses at the fishing grounds and is not a reflection of the efficacy of any methods employed to avoid catching birds, hence the decision not to include these sets in the analysis. We only considered the presence or absence of albatross species to determine whether or not to include a set in the analysis, as captures of other seabird species are very rare events in this fishery - of 310 seabirds observed captured in this fishery from 2 March 1994 to 4 September 2007, 6 (2\%) were a species other than black-footed or Laysan albatrosses. The pre-regulation period used for the purposes of the present study started on 9 May 2000, the date the observer program began recording seabird abundance during fishing operations, and ended on 9 June 2001, the day before seabird regulations went into effect. The postregulation study period was from 10 June 2001 through 4 September $2007^{2}$.

The number of birds hauled aboard is used to estimate the total number of seabirds captured during the set, despite evidence that this method underestimates total bird capture (Brothers 1991, Gales et al. 1998, Gilman et al. 2003, 2007a). Observers are not required to observe the entire setting of the gear, and therefore all seabird captures occurring during setting are not necessarily observed. Thus, observations of bird captures during setting operations were not used for this analysis.

It was not possible to normalize seabird bycatch rates for albatross abundance, as conducted in previ-

\footnotetext{
${ }^{2}$ At the time of conducting the query to the US National Marine Fisheries Service observer program database, the US National Marine Fisheries Service had not completed validating some of the observer data from longline tuna trips included in this analysis
} 
ous experiments (Gilman et al. 2003, 2005, 2007a). This was because seabird abundance was not estimated in a consistent manner throughout the entire study period, and observations were not made during the setting portion of the fishing operation of every set included in the analysis prior to 28 September 2004.

Spatial and temporal trends in seabird catch rates for the pre- and post-regulation sets were estimated using a nonparametric regression modeling approach known as generalized additive modeling (GAM). This method allows (1) flexible specification of the error and link functions, and (2) arbitrary specification of the functional form for each predictor included in the model (Hastie \& Tibshirani 1990). GAMs are the preferred choice for analysis of spatial and temporal trends in data series that may comprise nonlinear behavior and involve multi-level sampling designs (Fahrmeir \& Lang, 2001, Wood 2006). The GAM approach relaxes the normality assumptions of the standard linear regression modeling approach and supports flexible link specification, while the functional form (linear, nonlinear) for each predictor is estimated from the data using nonparametric smoothers while conditioning on other covariates in the model. The standard regression model for count data, such as number of seabirds caught in a specific time period, assumes the Poisson probability model structure (McCullagh \& Nelder 1989). Therefore, we fitted Poisson GAMs to the seabird catch using an offset term - offset(ln[hooks]) — to account for sampling effort measured as hooks per set. Hence, the response variable is the number of seabirds caught per set, but is now a standardized catch rate as sampling effort was also explicitly accounted for using the offset term. Informative covariates or factors included in the model were (1) time of day of set, (2) geographic location where sets were initiated, (3) season of set, and (4) whether the set was made during the pre-or post-regulation period. This nonparametric regression model was fitted using thin plate regression splines to model any nonlinear (time of day of initiating a set) or 2-dimensional effects (location of set). A quasi-Poisson error structure was employed to account for over-dispersed count data, as the data set comprised a large number of sets with zero seabird catches (McCullagh \& Nelder 1989). All smoothness parameters were determined using generalized cross-validation (Wood 2006). Models were fitted using the mgcv package (Wood 2006) available for the open source statistical modeling program $\mathrm{R}$ (Ihaka \& Gentleman 1996). Sullivan et al. (2006) employed a similar statistical method in a study of methods to reduce seabird mortality from striking warp cables in factory trawl vessels, accounting for over-dispersion by using a negative binomial error structure in a generalized linear model (GLM). Instead, we employed a quasi-Poisson error structure in a GAM to address over- dispersion because this is a far more flexible and general model that accounts for both over-dispersion and the nonlinear function form of the covariates (see Wood 2006).

We calculated estimates of seabird catch rates for the pre- and post-regulation periods, based on a binomial estimator with Clopper-Pearson confidence intervals (Agresti 2002), classified by the following informative factors which could affect the bird bycatch rates: $\leq 45 \mathrm{~g}$ vs. $>45 \mathrm{~g}$ branch line weighting, timing of the start of the set and season. We also determined the proportion of sets included in the sample that were made outside of the area where seabird bycatch reduction methods are required.

Alternative combinations of seabird avoidance methods. For a second study component, to compare alternative combinations of seabird avoidance methods, observer data collected from the Hawaii longline tuna fishery were analyzed for the period 15 August 2003 through 4 September 2007. On 15 August 2003 observers began recording whether vessels were setting from the stern or side of the vessel; hence the decision not to include observer program data prior to this date. For this study component, a set was included in the analysis if (1) one or more albatrosses was recorded as being present during the fishing operation; and/or (2) one or more seabirds (any species) was observed hauled aboard following that set.

Sets were categorized into one of 4 combinations of seabird avoidance methods:

(1) Side-setting with $45 \mathrm{~g}$ weights attached to branch lines within $1 \mathrm{~m}$ of hook;

(2) Side-setting with $60 \mathrm{~g}$ weights attached to branch lines within $1 \mathrm{~m}$ of hook;

(3) Stern-setting with $45 \mathrm{~g}$ weights attached to branch lines within $1 \mathrm{~m}$ of hook; or

(4) Stern-setting with $60 \mathrm{~g}$ weights attached to branch lines within $1 \mathrm{~m}$ of hook.

Spatial and temporal trends in seabird catch rates for the 4 categories of sets employed during the postregulation period and sets employed during the preregulation period were estimated by fitting Poisson GAMs to the seabird catch. Informative covariates included in the model were (1) time of day of set, (2) location where sets were initiated, (3) season of set, (4) whether or not bait was treated (thawed and dyed blue); and (5) which of the 4 pre-regulation categories the set fits or otherwise if the set was during the preregulation period. The GAM was fitted using thin plate regression splines to model any nonlinear effect (time of day of initiating a set) or 2-dimensional effect (location of set). Log link (ln[hooks]) was used in the offset term to account for hooks per set. A quasi-Poisson error structure was again employed to account for overdispersed count data (McCullagh \& Nelder 1989). All 
smoothness parameters were determined using generalized cross-validation (Wood 2006). Models were fitted using the mgcv package (Wood 2006) available for the program R (Ihaka \& Gentleman 1996).

We also combined these 4 categories into 2 categories of stern- vs. side-setting, and 2 categories of 45 vs. $60 \mathrm{~g}$ weights employed during the post-regulation period to determine if there was a significant difference in seabird catch rates between these 2 pairs of factors. Spatial and temporal trends in seabird catch rates were estimated by fitting Poisson GAMs to the seabird catch. For the side- vs. stern-setting comparison, informative covariates included in the model were (1) time of day of set, (2) location where sets were initiated, (3) season of set, (4) whether or not bait was treated (thawed and dyed blue); and (5) size of branch line weight. For the 45 vs. $60 \mathrm{~g}$ comparison, informative covariates included in the model were (1) time of day of set, (2) location where sets were initiated, (3) season of set, (4) whether or not bait was treated (thawed and dyed blue); and (5) whether sets were made from the side or the stern of the vessel.

We calculated estimates of seabird catch rates for the data, based on a binomial estimator with ClopperPearson confidence intervals (Agresti 2002), classified by the following informative factors which could affect the bird bycatch rates: side- vs. stern-setting, 45 vs. $60 \mathrm{~g}$ branch line weighting, timing of the start of the set and season. We also determined the frequency of voluntary employment of different seabird bycatch reduction methods at grounds where seabird avoidance methods are not required.

There were 215 sets where an albatross was observed during the fishing operation and/or a seabird was observed captured during the haul which were excluded from this main analysis because they did not fit into one of the 4 categories (e.g. sets where a towed deterrent or tori line was deployed, sets that were made at night, sets with line weighing less than $45 \mathrm{~g}$ including no weight, sets with atypical line weights, and sets where a leader length was $>1 \mathrm{~m}$ ). As with the first study component, the number of birds hauled aboard was used to estimate the total number of seabirds captured during the set, and it was not possible to normalize seabird capture rates by albatross abundance.

\section{RESULTS}

\section{Pre- vs. post-regulation period}

There were 702 sets of 1337224 hooks during the pre-regulation period, during which 107 seabirds were observed captured. There were 3800 sets of 7727429 hooks during the post-regulation period, during which 166 seabirds were observed captured. Table 1 provides a summary of the data used in the Poisson regression model. The pre- and post-regulation nominal seabird bycatch rates were 0.080 (95\% CI: 0.066 to 0.097 ) and 0.021 (95\% CI: 0.018 to 0.025) seabirds per 1000 hooks, respectively, a significant 74 percent reduction in the pre-regulation period seabird catch rate (Table 1).

Fig. 3 presents the Poisson GAM model fit to the seabird catch rate data for the combined 4502 pre- and post-regulation period sets. The 3 covariates or factors (time of starting setting operations, season in which a set was made, and location at the start of sets) included in the model were all significant effects. Timing of initiating setting was a significantly nonlinear effect. Seabird catch rates were lowest during October to December, and seabird catch rates in all 4 quarters of the year were significantly different from each other (Fig. 3a). Seabird catch rates were lowest during sets initiated between 0:00 to ca. 05:00 h, dipped slightly around 15:00 $\mathrm{h}$ and then increased during early evening (Fig. 3b). Higher seabird catch rates occurred around the main Hawaiian Islands, with the highest rates in the northwestern sector at ca. $25^{\circ} \mathrm{N}, 170^{\circ} \mathrm{W}$ (Fig. 3c). Based on the Poisson GAM model, conditioned on the 4 covariates or factors, the seabird catch rate decreased significantly by $67 \%$ (95\% CI: 62 to 72 ) from the pre- to post-regulation period (Fig. 3d). The model was a reasonable fit to the large data set and accounted for $38.2 \%$ of the model deviance.

Of the prescribed seabird bycatch reduction methods, branch line weighting is the one gear design that was also conventionally employed during the preregulation period. Perhaps due to the adoption of the seabird regulation line weighting requirement, the mean amount of weight used during the post-regulation period was significantly different and higher, although only by a small amount: During the pre-regulation period, vessels conventionally employed branch line weighting with a mean of $47.4 \mathrm{~g} \pm 0.4 \mathrm{SD}$, whereas the mean for the post-regulation period was $49.9 \mathrm{~g} \pm$ 0.1 SD. When the Poisson GAM model was modified to explicitly account for this variability in branch line weighting effect on seabird bycatch rate, by including branch line weighting as a covariate, branch line weighting was found to have a significant linear effect on seabird catch rate $(p<0.01)$. We did not include branch line weighting as a covariate in the model as this is one of the seabird bycatch reduction methods included in the regulations, and we needed the GAM model to be affected by the pre- vs. post-regulation variability in the seabird bycatch reduction methods prescribed in the regulations. Unlike branch line weighting, the other seabird avoidance methods in the regulations (side-setting, dyed and thawed bait, bird 
Table 1. Four dimensional contingency table providing summary statistics of seabird capture rates based on a binomial estimator with Clopper-Pearson confidence intervals (Agresti 2002) for Hawaii longline tuna sets for the time periods prior to and following the introduction of regulations to reduce seabird bycatch, for sets with seabird captures observed during gear hauling and/or where albatrosses were present during setting or hauling

\begin{tabular}{|c|c|c|c|c|c|c|c|c|}
\hline \multirow[t]{2}{*}{ Period } & \multirow[t]{2}{*}{$\begin{array}{l}\text { Weight within } \\
1 \mathrm{~m} \text { of hook }(\mathrm{g})\end{array}$} & \multirow[t]{2}{*}{ Season } & \multirow{2}{*}{$\begin{array}{l}\text { Time of } \\
\text { initiating set } \\
\text { (h) }\end{array}$} & \multirow[t]{2}{*}{$\begin{array}{l}\text { No. of } \\
\text { sets }\end{array}$} & \multirow[t]{2}{*}{$\begin{array}{l}\text { No. of } \\
\text { hooks }\end{array}$} & \multirow{2}{*}{$\begin{array}{c}\text { Seabirds } \\
\text { captured } \\
\text { (hauled } \\
\text { aboard) }\end{array}$} & \multicolumn{2}{|c|}{$\begin{array}{l}\text { Seabird bycatch rate } \\
\text { (per } 1000 \text { hooks) }\end{array}$} \\
\hline & & & & & & & $\begin{array}{l}\text { Point } \\
\text { estimate }\end{array}$ & $95 \%$ CI \\
\hline \multicolumn{9}{|c|}{$\begin{array}{l}\text { Pre-regulations: } \\
2 \text { Mar } 1994 \text { - } 9 \text { Jun } 2001\end{array}$} \\
\hline \multirow{4}{*}{\multicolumn{2}{|c|}{$\leq 45$}} & Jan-Jun & $\leq 7: 00$ & 71 & 144268 & 5 & 0.035 & $0.011-0.081$ \\
\hline & & & $>7: 00$ & 298 & 556336 & 63 & 0.113 & $0.087-0.145$ \\
\hline & & Jul-Dec & $\leq 7: 00$ & 31 & 58501 & 0 & 0.00 & $0.000-0.063$ \\
\hline & & & $>7: 00$ & 72 & 132271 & 2 & 0.015 & $0.002-0.055$ \\
\hline \multirow{5}{*}{\multicolumn{2}{|c|}{$>45$}} & Jan-Jun & $\leq 7: 00$ & 32 & 65650 & 2 & 0.030 & $0.004-0.110$ \\
\hline & & & $>7: 00$ & 142 & 268391 & 35 & 0.130 & $0.091-0.181$ \\
\hline & & Jul-Dec & $\leq 7: 00$ & 12 & 24471 & 0 & 0.000 & $0.000-0.151$ \\
\hline & & & $>7: 00$ & 44 & 87336 & 0 & 0.000 & $0.000-0.042$ \\
\hline & & & Total & 702 & 1337224 & 107 & 0.080 & $0.066-0.097$ \\
\hline \multirow{2}{*}{\multicolumn{9}{|c|}{$\begin{array}{l}\text { Post-regulations: } \\
\text { 10 Jun } 2001 \text { - } 4 \text { Sep } 2007\end{array}$}} \\
\hline & & & & & & & & \\
\hline \multirow{4}{*}{\multicolumn{2}{|c|}{$\leq 45$}} & Jan-Jun & $\leq 7: 00$ & 365 & 727802 & 6 & 0.008 & $0.003-0.018$ \\
\hline & & & $>7: 00$ & 1248 & 2504716 & 89 & 0.034 & $0.029-0.044$ \\
\hline & & Jul-Dec & $\leq 7: 00$ & 173 & 360516 & 1 & 0.003 & $0.0001-0.015$ \\
\hline & & & $>7: 00$ & 831 & 1716557 & 10 & 0.006 & $0.003-0.011$ \\
\hline \multirow{5}{*}{\multicolumn{2}{|c|}{$>45$}} & Jan-Jun & $\leq 7: 00$ & 229 & 470735 & 10 & 0.021 & $0.010-0.039$ \\
\hline & & & $>7: 00$ & 540 & 1101414 & 50 & 0.045 & $0.034-0.060$ \\
\hline & & Jul-Dec & $\leq 7: 00$ & 131 & 263751 & 0 & 0.000 & $0.000-0.014$ \\
\hline & & & $>7: 00$ & 283 & 581938 & 0 & 0.000 & $0.000-0.006$ \\
\hline & & & Total & 3800 & 7727429 & 166 & 0.021 & $0.018-0.025$ \\
\hline
\end{tabular}

curtain and management of discards) were generally only employed during the post-regulation period.

There was uneven seasonal distribution of effort, with $67,10,1$ and $22 \%$ of sets made during the first (January to March) through 4th quarters, respectively, during the pre-regulation period, and 36, 27, 11, and $26 \%$ of sets made during the first through 4 th quarters, respectively, during the post-regulation period. The Poisson GAM model explicitly accounted for the effect of seasonal distribution of effort on seabird bycatch rate. During the pre-regulation period, the seabird catch rates by quarter were 0.09 (95\% CI: 0.07 to 0.11 ), 0.16 (95\% CI: 0.10 to 0.25$)$, 0.00 (95\% CI: 0.00 to 0.43 ), and 0.007 (95\% CI: 0.001 to 0.02 ) seabirds per 1000 hooks, respectively, using a binomial estimator. During the post-regulation period, the seabird catch rates by quarter were 0.03 (95\% CI: 0.02 to 0.03 ), 0.04 (95\% CI: 0.03 to 0.05 ), 0.005 (95\% CI: 0.001 to 0.012 ), and 0.003 (95\% CI: 0.001 to 0.007) seabirds per 1000 hooks, respectively, using a binomial estimator. The seabird capture rates were significantly higher during the first 2 quarters of the year during both the pre- and postregulation periods. The seabird catch rates were significantly lower during the first 2 quarters of the postregulation period relative to the first 2 quarters of the pre-regulation period, but this was not the case for the latter 2 quarters of the year.

Of the 4502 sets where an albatross was observed present during setting or hauling operations and/or a seabird was hauled to the vessel during gear retrieval, $2448(54 \%)$ began at a location south of $23^{\circ} \mathrm{N}$. Of the 176 sets where one or more albatrosses were captured, $74(42 \%)$ began at a location south of $23^{\circ}$ N. Regulations require Hawaii longline tuna vessels to employ seabird bycatch reduction methods only when fishing north of $23^{\circ} \mathrm{N}$.

\section{Alternative combinations of seabird avoidance methods}

A total of 2001 sets of 4236556 hooks were included in this study component comparing seabird catch rates of 4 alternative combinations of seabird avoidance methods. There were 60 sets with one or more seabirds observed captured. Of these, 53 sets had one or more confirmed albatross species caught. Table 2 provides a summary of the data used in the Poisson regression model.

Post-regulations, seabird catch rates in all 4 categories of sets were significantly lower than the pre-regulation 

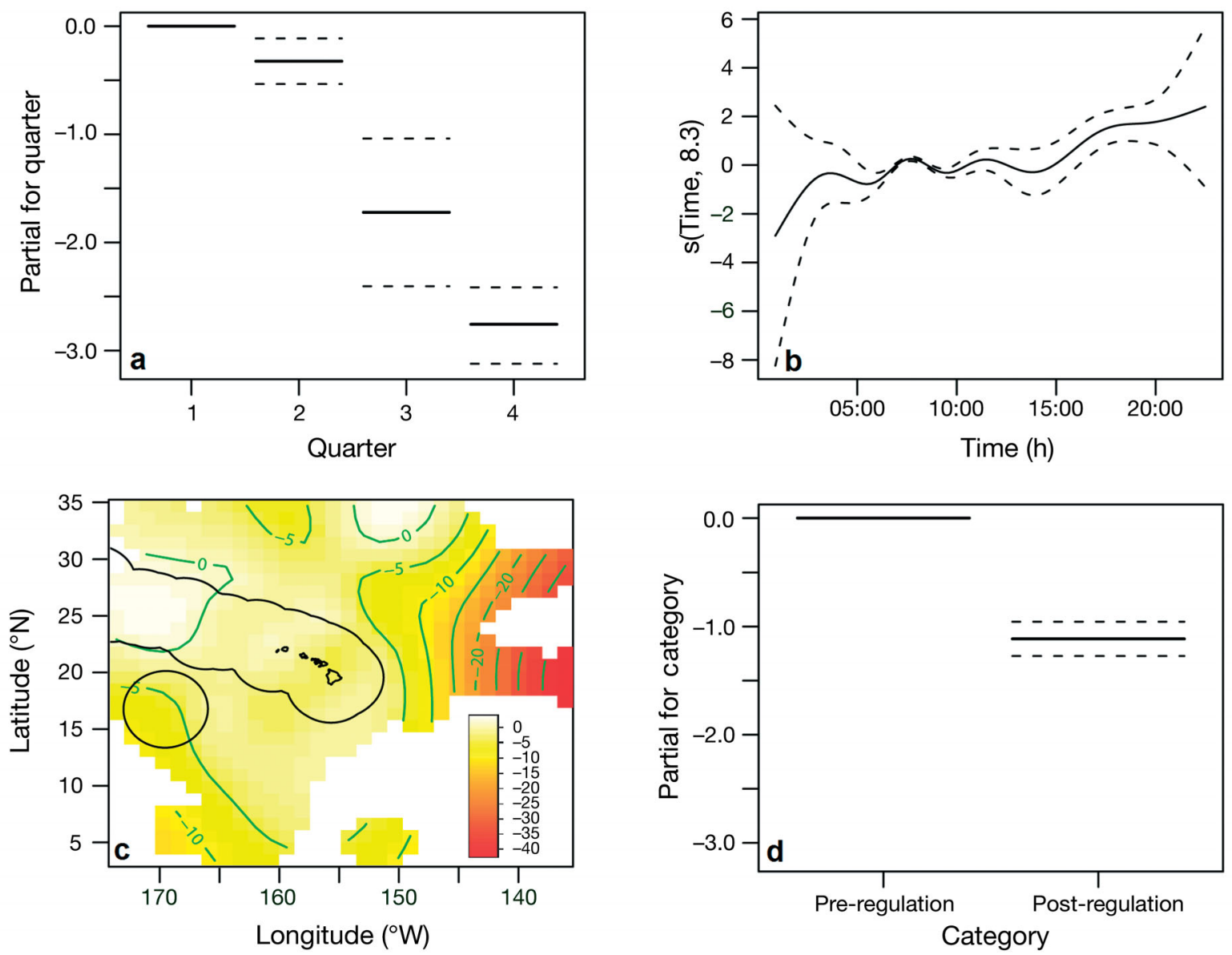

Fig. 3. Nonparametric Poisson regression model fitted to the seabird catch in sets made by the Hawaii longline tuna fishery during periods before $(n=702$ sets) and after $(n=3800$ sets $)$ mandatory seabird avoidance measures came into effect, for sets with seabird captures observed during gear hauling and/or with albatrosses present during setting or hauling. (a) Seabird catch rate as a seasonal effect conditioned on the other 3 factors of time of initiating setting, location of initiating sets, and pre- and postregulation period. (b) Set time effect in the model. (c) Two-dimensional spatial (setting location) effect of catch rate; the US Exclusive Economic Zone seaward boundary is shown (solid black lines). (d) Pre- and post-regulation period effect conditioned on the other 3 covariates. In (a) and (d) solid bars = mean, dashed bars $=95 \%$ confidence interval, $y$-axis $=$ centered response scale. In $(b)$ solid curves $=$ model fit, dashed curves $=95 \%$ pointwise confidence bands. Reference levels are centered at zero and are as follows: (a) the first quarter of the year (January to March), (d) the pre-regulation period

period catch rate (Fig. 4d), based on the Poisson GAM conditioned for the 3 factors. Side-setting with $45 \mathrm{~g}$ weights located within $1 \mathrm{~m}$ of the hook resulted in a seabird catch rate $40 \%$ (95\% CI: 28 to 58) lower than the pre-regulation seabird catch rate. No seabirds were caught in sets employing the combination of side-setting with $60 \mathrm{~g}$ weights located within $1 \mathrm{~m}$ of the hook. Stern setting with $45 \mathrm{~g}$ weights located within $1 \mathrm{~m}$ of the hook resulted in a seabird catch rate $60 \%$ (95\% CI: 44 to 82 ) lower, and stern setting with $60 \mathrm{~g}$ weights located within $1 \mathrm{~m}$ of the hook $41 \%$ (95\% CI: 27 to 62 ) lower than the pre-regulation seabird catch rate. There was no significant difference in seabird catch rates between the 3 categories of sets where birds were caught (Fig. 4d). The 4 covariates or factors - time of starting setting opera- tions, season in which a set was made, location at the start of sets, and whether or not bait was treated (dyed blue and thawed) - were found to have significant effects on seabird bycatch. Timing of initiating setting was a significantly nonlinear effect. Fig. 4a shows that seabird catch rates were lowest during October to December, and that the seabird catch rate in the 4th quarter was significantly lower than in the other 3 quarters. Seabird catch rates were lowest during sets initiated at 0:00 h, increased as time of setting advanced through ca. 04:30 $\mathrm{h}$ and remained at that level for start times through mid-afternoon (Fig. 4b). As observed in Fig. 3c, higher seabird catch rates occurred around the main Hawaiian Islands and the highest rates were in the northwestern sector ca. $25^{\circ} \mathrm{N}, 170^{\circ} \mathrm{W}$ (Fig. $4 \mathrm{c}$ ). Sets employing blue- 
Table 2. Four-dimensional contingency table providing summary statistics of seabird capture rates based on a binomial estimator with Clopper-Pearson confidence intervals (Agresti 2002) for Hawaii longline tuna sets from 15 August 2003 to 4 September 2007

\begin{tabular}{|c|c|c|c|c|c|c|c|c|}
\hline \multirow{2}{*}{$\begin{array}{l}\text { Bird bycatch } \\
\text { reduction } \\
\text { method }\end{array}$} & \multirow[t]{2}{*}{$\begin{array}{l}\text { Weight within } \\
1 \text { m of hook (g) }\end{array}$} & \multirow[t]{2}{*}{ Season } & \multirow{2}{*}{$\begin{array}{c}\text { Time of } \\
\text { initiating set } \\
\text { (h) }\end{array}$} & \multirow[t]{2}{*}{$\begin{array}{l}\text { No. of } \\
\text { sets }\end{array}$} & \multirow[t]{2}{*}{$\begin{array}{l}\text { No. of } \\
\text { hooks }\end{array}$} & \multirow{2}{*}{$\begin{array}{c}\text { Seabirds } \\
\text { captured } \\
\text { (hauled } \\
\text { aboard) }\end{array}$} & \multicolumn{2}{|c|}{$\begin{array}{l}\text { Seabird bycatch rate } \\
\text { (per } 1000 \text { hooks) }\end{array}$} \\
\hline & & & & & & & $\begin{array}{l}\text { Point } \\
\text { estimate }\end{array}$ & $95 \%$ CI \\
\hline \multirow[t]{9}{*}{ Side-setting } & 45 & Jan-Jun & $\leq 7: 00$ & 25 & 47108 & 1 & 0.021 & $0.001-0.118$ \\
\hline & & & $>7: 00$ & 114 & 244063 & 10 & 0.041 & $0.020-0.075$ \\
\hline & & Jul-Dec & $\leq 7: 00$ & 13 & 31346 & 0 & 0.000 & $0.000-0.118$ \\
\hline & & & $>7: 00$ & 102 & 218476 & 1 & 0.005 & $0.0001-0.026$ \\
\hline & 60 & Jan-Jun & $\leq 7: 00$ & 28 & 60659 & 0 & 0.000 & $0.000-0.061$ \\
\hline & & & $>7: 00$ & 63 & 138200 & 0 & 0.000 & $0.000-0.027$ \\
\hline & & Jul-Dec & $\leq 7: 00$ & 8 & 19074 & 0 & 0.000 & $0.000-0.193$ \\
\hline & & & $>7: 00$ & 15 & 34996 & 0 & 0.000 & $0.000-0.105$ \\
\hline & & & Total & 368 & 793922 & 12 & 0.015 & $0.008-0.026$ \\
\hline \multirow[t]{9}{*}{ Stern-setting } & 45 & Jan-Jun & $\leq 7: 00$ & 196 & 413905 & 2 & 0.005 & $0.001-0.017$ \\
\hline & & & $>7: 00$ & 556 & 1169204 & 25 & 0.021 & $0.014-0.032$ \\
\hline & & Jul-Dec & $\leq 7: 00$ & 51 & 110073 & 0 & 0.000 & $0.000-0.034$ \\
\hline & & & $>7: 00$ & 420 & 905543 & 6 & 0.007 & $0.002-0.014$ \\
\hline & 60 & Jan-Jun & $\leq 7: 00$ & 45 & 86891 & 0 & 0.000 & $0.000-0.042$ \\
\hline & & & $>7: 00$ & 215 & 440904 & 7 & 0.016 & $0.006-0.033$ \\
\hline & & Jul-Dec & $\leq 7: 00$ & 24 & 48602 & 0 & 0.000 & $0.000-0.076$ \\
\hline & & & $>7: 00$ & 126 & 267512 & 0 & 0.000 & $0.000-0.014$ \\
\hline & & & Total & 1633 & 3442634 & 40 & 0.012 & $0.008-0.016$ \\
\hline
\end{tabular}

dyed and thawed bait had a seabird catch rate $22 \%$ (95\% CI: 15 to 31) lower than sets using untreated bait; the difference was statistically significant (Fig. 4e). The model was a reasonable fit to the large data set, accounting for ca. $45.4 \%$ of the model deviance.

Based on a Poisson GAM model fit to 2 categories of sets made during the post-regulation period of those made from the side vs. the stern of the vessel, conditioned on the factors of time of starting setting, season, location at the start of sets, branch line weighting, and whether or not bait was thawed and dyed blue, there was no significant difference in seabird bycatch rates between side- vs. stern-setting at the $95 \%$ confidence level ( $p=0.14)$, but there was a significant difference at the $85 \%$ level $(\mathrm{p}<0.15)$. Side-setting resulted in seabird catch rate $21 \%$ (95\% CI: -8 to 42 ) lower than stern-setting.

There was a significant difference in seabird catch rates between sets made during the post-regulation period with $45 \mathrm{~g}$ weights located within $1 \mathrm{~m}$ of the hook and sets with $60 \mathrm{~g}$ weights within $1 \mathrm{~m}$ of the hook, when employing a Poisson GAM model fit to sets employing 45 vs. $60 \mathrm{~g}$ weights, conditioned on the factors of time of starting setting, season, geolocation of the start of sets, side- vs. stern-setting, and whether or not bait was thawed and dyed blue $(p<0.01)$. Sets with $60 \mathrm{~g}$ weights resulted in a seabird catch rate $63 \%$ (95\% CI: 45 to 88 ) lower than sets with $45 \mathrm{~g}$ weights.
Of the 2001 sets in this study component, 883 sets ( $44 \%$ of the sample) were initiated south of $23^{\circ} \mathrm{N}$ where either an albatross was observed to be present during setting or hauling and/or a seabird was captured. One or more of the seabird avoidance methods were employed during these 883 sets. Side-setting was employed in 131 sets, blue-dyed bait was used in 44 sets, and weights of $45 \mathrm{~g}$ or more were used in 855 of the sets (no branch line weights were used in 28 sets). In the 869 sets employing weights, weights were attached to branch lines within $1 \mathrm{~m}$ of the hook in all but 6 of the sets, in 55 sets offal was discarded on the side of the vessel opposite to that where the sets were made, a tori (bird scaring) line was deployed during 13 sets, a towed buoy was deployed during 9 sets, and 1 set was made at night.

\section{DISCUSSION}

\section{Seabird bycatch rates}

A Poisson GAM, conditioned on time of day of setting, season and location of setting predicted that the seabird capture rate declined significantly by $67 \%$ following the introduction of seabird regulations. By explicitly accounting for these covariates and factors, this modeling approach provided a strong inference of the effect of regulatory measures involving changes in fish- 

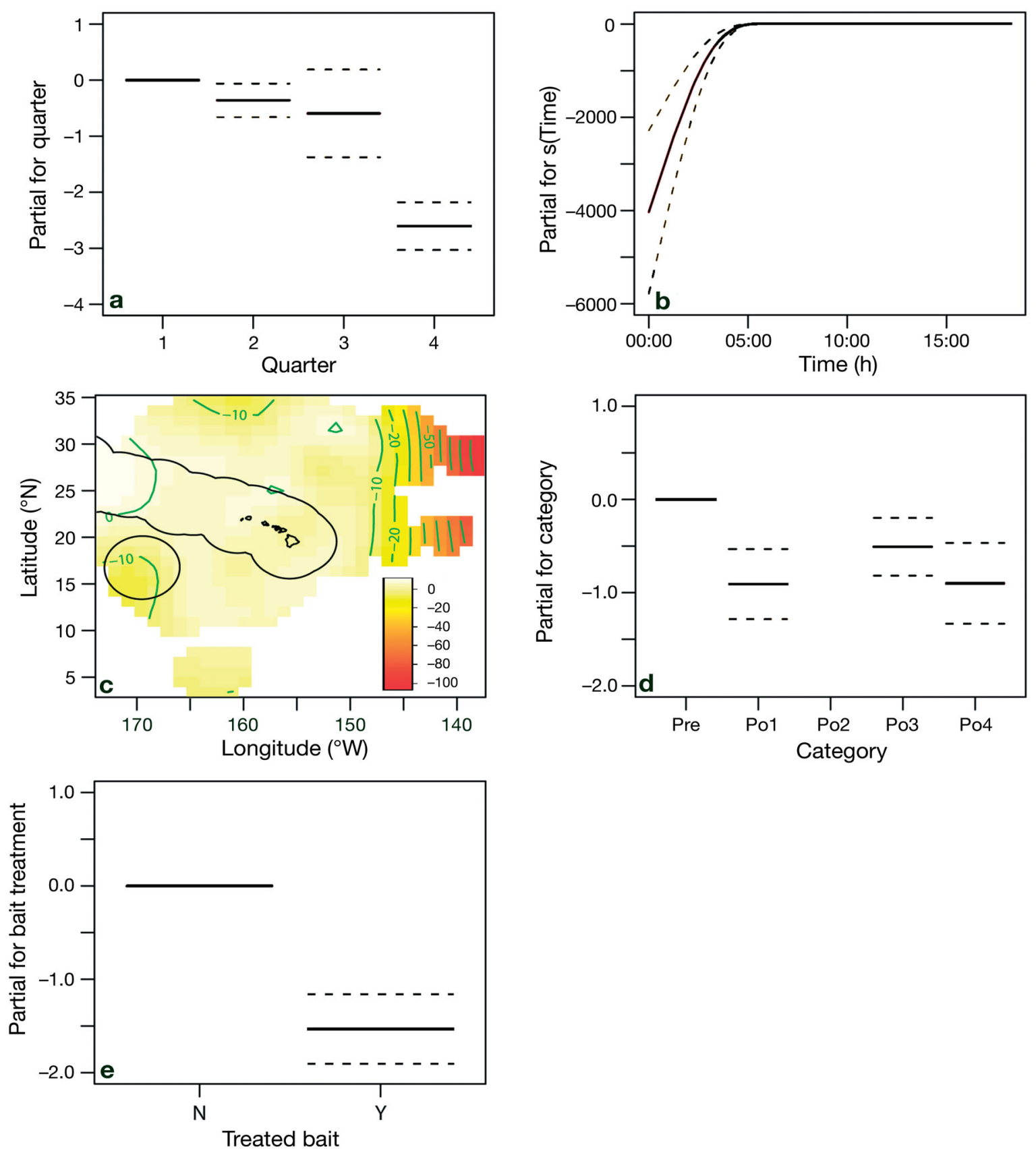

Fig. 4. Nonparametric Poisson regression model fitted to the seabird catch in sets made by the Hawaii longline tuna fishery during the period prior to seabird avoidance regulations coming into effect ( $\mathrm{n}=702$ sets) and for 4 categories of seabird bycatch avoidance methods (see 'Methods; Alternative combinations of seabird avoidance methods') employed by the Hawaii longline tuna fishery during the post-regulations period $(\mathrm{n}=254,114,1223$, and 410 sets in the order displayed), for sets with seabird captures observed during gear hauling and/or albatrosses present during setting or hauling. (a) Seabird catch rate as a seasonal effect conditioned on the other 4 factors time of initiating setting, location of initiating sets, 5 categories of sets, and bait treatment (untreated vs. dyed blue and thawed). (b) Set time effect in the model. (c) Two-dimensional spatial (setting location) effect on catch rate; the US Exclusive Economic Zone seaward boundary is shown. (d) Effect of the 5 categories of sets conditioned on the other covariates. Pre = pre-regulations period; Po1 = side-setting with $45 \mathrm{~g}$ weights located within $1 \mathrm{~m}$ of the hook; Po2 = sidesetting with $60 \mathrm{~g}$ weights located within $1 \mathrm{~m}$ of the hook (note, the $y$-value of -132.9 puts this category off the scale of the figure); Po3 = stern-setting with $45 \mathrm{~g}$ weights located within $1 \mathrm{~m}$ of the hook; Po4 = stern-setting with $60 \mathrm{~g}$ weights located within $1 \mathrm{~m}$ of the hook. (e) Bait treatment effect in the model: $\mathrm{N}=$ no (untreated), $\mathrm{Y}=$ yes (dyed blue and thawed). In (b) solid curves $=$ model fit, dashed curves $=95 \%$ pointwise confidence bands. In $(a, d, e)$ solid bars $=$ mean, dashed bars $=95 \%$ confidence interval, $y$-axis $=$ centered response scale. Reference levels are centered at zero and are as follows: (a) the first quarter of the year (January to March), (d) the pre-regulation period, (e) no bait treatment 
ing gear and fishing methods. The actual, observed change in seabird bycatch rates from pre- to postregulation periods was a significant $74 \%$ reduction (Table 1). Results demonstrate that there are several effective methods for seabird avoidance in pelagic longline fisheries. After the regulations came into effect, sets employing 4 different combinations of seabird bycatch reduction methods all reduced seabird catch rates by more than $40 \%$ relative to the pre-regulation rate.

Results suggest that substantial seabird bycatch reduction is realized by the use of $60 \mathrm{~g}$ weights, bluedyed and thawed bait, and perhaps side-setting, which are components of current regulations. The timing of setting and temporal and spatial distribution of effort also significantly affected seabird catch rates, and represent potential additional strategies for further reductions in seabird bycatch in the Hawaii longline tuna fishery. Additional assessment is needed to determine to what degree bycatch would likely be reduced by alternative, additional management measures involving restrictions on fishing gear and methods or temporal and spatial restrictions on fishing effort, and at what cost.

To provide a rough understanding of potential seabird conservation benefits, restricting the initiating of sets to 7:00 $\mathrm{h}$ or earlier $(\leq 7: 00 \mathrm{~h})$ results in a seabird catch rate that is $69 \%$ (and significantly) lower than when sets are made after 7:00 h (>7:00 h): sets initiated $\leq 7: 00 \mathrm{~h}$ resulted in a seabird catch rate of 0.011 seabirds per 1000 hooks (95\% CI: 0.007 to 0.017 ), while sets initiated after $7.00 \mathrm{~h}$ resulted in a seabird catch rate of 0.036 (95\% CI: 0.031 to 0.041 ) (based on a binomial estimator with Clopper-Pearson confidence intervals) (Table 1, Fig. 3b). It is likely that avoiding setting during local dawn and dusk periods, when albatrosses most actively forage, is key (Brothers et al. 1999). Similarly, sets made during the first half of the year resulted in a seabird catch rate an order of magnitude higher than those in the latter half of the year: In the first half of the year, the seabird catch rate of 0.045 (95\% CI: 0.039 to 0.050 ) was $91 \%$ higher than during the second half of the year, when it was 0.0040 (95\% CI: 0.002 to 0.007) (Table 1, Fig. 3a). Sets made north of $24^{\circ} \mathrm{N}$ and west of $170^{\circ} \mathrm{W}$ had a seabird catch rate of 0.84 birds per 1000 hooks (95\% CI: 0.62 to 1.11 , only 28 sets), an order of magnitude and significantly higher than the bird catch rate of sets made in the rest of the fishing grounds $(0.025$ birds per 1000 hooks [95\%CI: 0.022 to 0.028], Table 1, Fig. 3d). These 3 examples do not explicitly account for other factors that affect seabird bycatch rates. For example, the 28 sets made in the alleged seabird bycatch hotspot might have included an outlier (a single set with a high number of bird captures), or the high seabird catch rate could have been due to some aspect of the fishing gear or methods employed in these sets. These rough assessments strengthen the finding that timing of setting and temporal and spatial distribution of effort significantly affected seabird catch rates, and present a potential management tool for further seabird bycatch reductions which warrant additional assessment.

\section{Experimental vs. commercial conditions}

Despite the observed efficacy of a bycatch avoidance method during experimental conditions, fishers may not employ the method as prescribed or, indeed, at all if it is not convenient and economically viable and if incentives, including enforcement, are insufficient (Gilman et al. 2005, Cox et al. 2007). In the present study we observed smaller reductions in bird catch rates due to side-setting and blue-dyed bait (21 and $22 \%$ reductions, respectively) than found in experiments testing the single factor effects of these seabird bycatch reduction methods. Two experiments in the Hawaii longline fishery found the single factor effect of employing blue-dyed fish bait reduced seabird captures by 63 and $95 \%$, and one experiment found that side-setting eliminated seabird captures (McNamara et al. 1999, Gilman et al. 2005, 2007a). The smaller reductions in seabird catch rates observed here relative to the experiments may be because these 2 seabird bycatch reduction methods allowed for deviation from their experimental and prescribed employment (e.g. crew may not have thrown baited hooks as close to the vessel hull or as far forward when side-setting as in the experiment, crew may not have completely thawed bait, soaked the bait in dye for sufficient time, or used the prescribed concentration of blue dye as in the experiments).

The observed $63 \%$ lower seabird catch rate for sets employing $60 \mathrm{~g}$ weights relative to those using $45 \mathrm{~g}$ is larger than expected, given that the difference in the baited hook sink rates between these 2 gear designs is only about $0.1 \mathrm{~m} \mathrm{~s}^{-1}$ (Brothers \& Gilman 2007) Because line weighting is a seabird bycatch reduction strategy that does not result in differences in employment as a result of crew behavior, we would expect bird catch rate reductions to be consistent with those found in controlled experiments. Boggs (2001) found a $92 \%$ reduction in seabird contacts with fishing gear in the Hawaii longline swordfish fishery as a result of

\footnotetext{
${ }^{3}$ The mean baited hook sink rate of branch lines containing a $45 \mathrm{~g}$ swivel at $300 \mathrm{~mm}$ from a tuna 3.6 hook was observed to be $1.2 \mathrm{~m} \mathrm{~s}^{-1}$. This increased to $1.3 \mathrm{~m} \mathrm{~s}^{-1}$ for a branch line containing a $60 \mathrm{~g}$ swivel attached at $300 \mathrm{~mm}$ from a tuna 3.6 hook (Brothers \& Gilman 2007)
} 
adding a $60 \mathrm{~g}$ weight at the hook, but did not determine the effect on seabird catch rate; thus, his results are of limited utility for comparison with the observed effect of line weighting reported here.

\section{Benefits and limitations of studies of observer data}

The use of observer data to compare catch rates from a marine capture fishery is inherently limited in not allowing for the control of confounding factors. Gilman et al. (2005) observed that, when comparing seabird bycatch rates for avoidance methods from 2 different experiments, even when normalized for seabird abundance, the combined effect from numerous variables can result in significantly different seabird bycatch rates even for the same treatment used in different experiments. Because results in this and most other studies were not reported as normalized for seabird abundance, this alone substantially reduces the ability to meaningfully compare results between studies (Gilman et al. 2003, 2005). Albatross abundance is likely to change by area for each season of different years, as albatross at-sea abundance may be correlated with the proximity to breeding colonies during the breeding season as well as the location of largescale oceanographic features and short-lived hydrographic features such as eddies and fronts (Hyrenbach et al. 2000). In addition to seabird abundance during fishing operations, variability may also result from several additional factors not explicitly accounted for in our models, including fishing gear and methods (e.g. use of deck lighting at night, offal discharge practices, type and condition of bait, length of branch lines, size and type of hooks, crew practices for deploying branch lines), environmental parameters (e.g. weather, bird behavior, bird species complex), and consistency in observers' methods and fishers' behavior (Brothers 1991, Brothers et al. 1999, Gilman 2001). For example, with seabird regulations in effect, fishers may have an increased incentive to conceal caught seabirds from onboard observers, for example, by dropping branch lines containing caught seabirds before an observer notices the bycatch. This is a documented problem in some fisheries with seabird bycatch management measures (Gales et al. 1998, Gilman et al. 2005). Seabird foraging behavior around fishing vessels may also be influenced by variations in regional climate, such as phases of the El Niño Southern Oscillation (during less productive La Niña phases, seabirds may be more abundant and aggressive around fishing vessels), and may further be variable depending on the seabird species complex in the vicinity of a fishing vessel.

While controlled and comparative studies permit drawing more definitive conclusions on causality of differences in catch rates between treatments, analyses using observer program data typically enable much larger sample sizes relative to controlled and comparative experiments. Furthermore, analysis of observer data enables an assessment of the status and trends in bycatch rates in the fishery, fundamental information needed to guide responsible fisheries management. Such information is not as reliable when obtained from scientific experiments, because during these experiments, fishing methods and gear, and fisher behavior, are not likely characteristic of normal operations (Gilman et al. 2005, Cox et al. 2007). Observational studies often arise in the area of medicine, where it may be unethical to employ a control group. Similar ethical, as well as ecological, issues arise when dealing with endangered and threatened species when it behooves researchers to consider alternative study designs to controlled experiments, including comparative studies and observer data analyses.

\section{Seabird abundance during setting}

During the study period (9 May 2000 to 4 September 2007), observers did not record albatross presence during setting or hauling for $7 \%$ of sets with observed albatross captures (13 of 181 sets), indicating that the current protocol for recording seabird abundance could be improved. Gilman et al. (2003, 2007a) employed a standardized method to estimate mean albatross abundance during setting: Every 15 min throughout each set a count of each seabird species within a 500 by $500 \mathrm{~m}$ square area astern of the vessel was recorded (within $250 \mathrm{~m}$ of port and starboard of the center of the vessel stern and within $500 \mathrm{~m}$ behind the vessel). The Hawaii longline observer program should define a similar area around the vessel for observers to improve consistency of measurements of mean seabird abundance during sets. More importantly, increasing the number of seabird abundance estimates during setting operations, and collecting data throughout the set, and not just during the initial $30 \mathrm{~min}$, would enable a better characterization of seabird abundance for the entire set. Currently, observers estimate seabird abundance primarily during gear hauling. Observations of seabird abundance during hauling likely provide an inaccurate characterization of seabird abundance during the period when birds are being captured because (1) seabird captures occur primarily during setting in this fishery (Gilman et al. 2003, 2005), (2) albatross abundance is generally lower at night than during the day, and (3) it is difficult to accurately estimate bird abundance around the vessel in the dark (McNamara et al. 1999). 
However, because observers need to observe each haulback in full in order to record the number of seabirds captured, interactions with other protected species (sea turtles and marine mammals), handle and release any protected species brought to the vessel alive during the haul, and record other fundamental information, an additional requirement for an observer to also watch entire setting operations would leave insufficient time to sleep and eat. However, it may be feasible for observers to record albatross abundance during the first and last hour of each set, which would better characterize seabird abundance during setting than the current method.

\section{Fishing grounds where seabird bycatch is problematic}

A large proportion of albatross interactions with the Hawaii longline tuna fishery occurred south of $23^{\circ} \mathrm{N}$, the southern boundary ofthe area for required employment of prescribed seabird avoidance methods by Hawaii longline tuna vessels. Management authorities originally selected this boundary to reduce the risk of interactions with the short-tailed albatross Phoebastri albatrus (US Fish and Wildlife Service 2002, 2004, US National Marine Fisheries Service 2005). However, the stated purpose of current regulations is to reduce interactions with all seabird species, not just the listed endangered short-tailed albatross (US Western Pacific Fishery Management Council 2004, US National Marine Fisheries Service 2005). Based on observations of where the fleet catches seabirds, to more effectively minimize seabird bycatch rates in the Hawaii longline tuna fishery, fishery management authorities should consider moving the boundary for the prescribed use of seabird avoidance measures farther south.

\section{Voluntary use of seabird avoidance strategies}

Of the seabird avoidance methods voluntarily employed by the Hawaii longline tuna vessels when fishing at grounds where seabird avoidance methods are not required, besides the conventional practice of attaching weighted swivels near the hook, fishers demonstrated the most frequent voluntary use of side setting. The analysis of the sets included in this analysis for the employment of seabird avoidance methods at fishing grounds where bird avoidance methods are not required showed that fishers frequently voluntarily attach weights of $45 \mathrm{~g}$ or more within $1 \mathrm{~m}$ of the hook (92\% of sets). Of the other seabird avoidance methods, side-setting was employed the most frequently $(15 \%$ of sets), followed by discarding offal on the opposite side of the setting operation (6\%), blue-dyed bait $(5 \%)$, tori line $(1 \%)$, towed buoy $(1 \%)$, and night setting $(0.3 \%)$.

These results are consistent with the findings of Gilman et al. $(2005,2007 a)$ that side-setting presented several operational benefits to Hawaii longline vessel crew, while blue-dyed bait was reported by crew to be impractical for several reasons. This suggests that compliance with a required employment of side-setting is likely to be higher than for other seabird avoidance methods, even when an observer is not present and in fisheries lacking resources for a high degree of surveillance and enforcement.

\section{CONCLUSIONS}

Catch rates of seabirds were significantly reduced after seabird protection regulations came into effect in the Hawaii longline tuna fishery. This study documented the efficacy of different combinations of commercially employed seabird bycatch reduction methods, demonstrating that there are several extremely effective methods for seabird avoidance in pelagic longline fisheries. Findings indicate that in the Hawaii longline tuna fishery, using heaver branch line weights (in particular, 60 instead of $45 \mathrm{~g}$ weights within $1 \mathrm{~m}$ from the hook), blue-dyed and thawed bait instead of untreated bait, and possibly side-setting instead of stern-setting are effective methods, involving differences in fishing gear and practices, to achieve large and significant reductions in seabird catch rates. Furthermore, time-area closures and restrictions on the timing of setting could further reduce seabird bycatch, as these factors were observed to have significant effects on seabird catch rates.

The efficacy of a bycatch avoidance method observed during experimental conditions may not be achieved during commercial fishing operations because the methods in the experiments may not be employed as prescribed or may not be used at all by fishers if they are not convenient and economically viable and if incentives, including enforcement, are insufficient (Gilman et al. 2005, Cox et al. 2007). This may be the case with blue-dyed and thawed bait and side-setting. However, results suggest that, at least when an observer is onboard, the Hawaii longline tuna fleet is employing seabird avoidance measures and this has resulted in large and significant reductions in seabird catch rates relative to the pre-regulations period, even when fishing at grounds where the employment of these measures are not mandatory. Consistent with previous results of commercial demonstrations in this fishery (Gilman et al. 2007a), sidesetting, a conventional practice, was the second most 
common measure (after branch line weighting) voluntarily employed by vessels on fishing grounds where seabird avoidance methods were not required. This suggests that compliance with required employment of side-setting is likely to be higher than other seabird bycatch reduction methods.

Efforts by the Hawaii longline fleet alone to reduce seabird bycatch will not reverse North Pacific albatross population decline. The Hawaii longline fleet is a very small component of the total longline fishing effort in the North Pacific, representing less than $3 \%$ of total longline hooks deployed in the Pacific Ocean each year (Majkowski 2007). Of the 61 species of seabird affected by longline fisheries, 26 are threatened with extinction, including 19 species of albatrosses, among them the Laysan and black-footed albatrosses, and there is compelling evidence that longline mortality is a significant component in the decline of many of these species (Gales et al. 1998, Brothers et al. 1999, Lewison \& Crowder 2003, Niel \& Lebreton 2005).

The seabird avoidance methods found to be effective in the Hawaii fishery may likewise be effective in other longline fisheries. However, different seabird avoidance methods may be appropriate for different longline fisheries due to differences in the diving abilities of seabird species that interact with each fishery, vessel designs, and fishing gear and methods (Brothers et al. 1999, Gilman et al. 2005). In particular, the very rare occurrence of interactions with deep-diving species of seabirds in the Hawaii fishery, and use of relatively large weights proximate to the hook, are important differences that need to be taken into account when considering the applicability of results from this study to other fleets. Trials in individual fisheries must precede advocacy for the introduction of specific seabird avoidance methods.

Despite the availability of effective avoidance methods that also increase fishing efficiency, most longline fleets do not employ effective seabird avoidance methods (Brothers et al. 1999, Gilman et al. 2005). Some Regional Fisheries Management Organizations (RFMOs) have recently made progress: 5 have adopted legally binding conservation measures related to reducing seabird bycatch in pelagic and demersal longline and trawl fisheries (Gilman et al. 2007b). However, these RFMO seabird conservation measures need to be improved. For instance, the areas where some of these measures are required do not include higher latitude fishing grounds, where seabird interactions have been observed to be problematic. The measure adopted by the Western and Central Pacific Fisheries Commission does not require vessels $<24 \mathrm{~m}$ in length to employ seabird avoidance measures in areas north of $23^{\circ} \mathrm{N}$; however, the present and previous studies have documented high seabird bycatch rates by vessels in this size category in this area. Furthermore, compliance by many member states with these RFMO seabird conservation measures is likely low, as observer programs and national management frameworks are generally weak or nonexistent, preventing definitive assessments. For example, 40 nations worldwide are engaged in longline fishing, of which only 15 have observer programs (Beverly \& Chapman 2007). There have been few voluntary longline industry actions to address seabird bycatch (Gilman \& Lundin 2008).

Recognizing this context of global longline fisheries management, it is necessary to maximize industry's sense of ownership for effective seabird avoidance measures and to provide industry with economic and other incentives for voluntary compliance. Identifying measures that are practical and convenient for the crew as well as being economically viable - or better yet, that provide operational and economic advantages will maximize the chance that effective bycatch reduction methods will be used by the fishing industry (Gilman et al. 2005). Scientifically rigorous eco-labeling and other certification programs for marine capture fisheries, and adoption of suitable sustainable seafood sourcing policies by retailers and seafood buyers, provide large market-based and social incentives for some fisheries to meet sustainability criteria (e.g. Alaska Seafood Marketing Institute 2001, Johnston et al. 2001, FAO 2008). These emerging market-based incentives may eventually become the most effective factor for the tuna industry to improve the sustainability of their practices (IUCN and Western Pacific Fishery Management Council 2008).

Acknowledgements. Funding for this study was kindly provided by the US National Marine Fisheries Service, Pacific Islands Regional Office. Brent Miyamoto, US National Marine Fisheries Service, Pacific Islands Fisheries Science Center, extracted observer data for the Hawaii longline fishery, provided insightful comments and suggestions for the design of data queries, and provided helpful comments on a draft of this report. Stuart 'Joe' Arceneaux, Kevin Busscher, and Lewis Van Fossen, US National Marine Fisheries Service, Pacific Islands Regional Office, provided information on observer data collection protocols and offered constructive comments on drafts of the manuscript. Evan Howell and Dean Courtney, US National Marine Fisheries Service, Pacific Islands Fisheries Science Center, 3 anonymous reviewers, and the Theme Section editor provided helpful comments on a draft manuscript.

\section{LITERATURE CITED}

Agresti A (2002) Categorical data analysis. Wiley, New York Alaska Seafood Marketing Institute (2001) Whole foods stores carry Alaska salmon with eco-label. Marketline (June): 1

Beverly S, Chapman L (2007) Interactions between sea turtles and pelagic longline fisheries. Western and Central Pacific 
Fisheries Commission, Scientific Committee, 3rd Regular Session, 13-24 August 2007, Honolulu. Information Paper WCPFC-SC3-EB SWG/IP-01. Western and Central Pacific Fisheries Commission, Palikir

Beverly S, Chapman L, Sokimi W (2003) Horizontal longline fishing methods and techniques: a manual for fishermen. Secretariat of the Pacific Community, Noumea

Boggs CH (2001) Deterring albatrosses from contacting baits during swordfish longline sets. In: Melvin E, Parrish K (eds) Seabird bycatch: trends, roadblocks, and solutions. University of Alaska Sea Grant AK-SG-01-01, Fairbanks, AK, p 79-94

Brothers NP (1991) Albatross mortality and associated bait loss in the Japanese longline fishery in the southern ocean. Biol Conserv 55:255-268

Brothers N, Gilman E (2007) Technical assistance for Hawaii pelagic longline vessels to change deck design and fishing practices to side set. Hawaii Longline Association, US NOAA Fisheries Pacific Islands Fisheries Science Center and Pacific Islands Regional Office, and Western Pacific Regional Fishery Management Council, Honolulu, HI. Available at: www.wpcouncil.org/pelagic/Documents/ Exec_sum_Side_set_tech_assist_HI.pdf

Brothers NP, Cooper J, Lokkeborg S (1999) The incidental catch of seabirds by longline fisheries: worldwide review and technical guidelines for mitigation. FAO Fish Circ 937. Food and Agriculture Organization of the United Nations, Rome

Cousins K, Cooper J (eds) (2000) The population biology of the black-footed albatross in relation to mortality caused by longline fishing. Report of a workshop held in Honolulu, Hawaii, 8-10 October 1998 by the US Western Pacific Regional Fishery Management Council, Honolulu, HI

Cox TM, Lewison RL, Zydelis R, Crowder L, Safina C, Read J (2007) Comparing effectiveness of experimental and implemented bycatch reduction measures: the ideal and the real. Conserv Biol 21:1155-1164

Fahrmeir L, Lang S (2001) Bayesian inference for generalised additive mixed models based on Markov random field priors. Appl Stat 50:201-220

FAO (2008) Ecolabels and marine capture fisheries: current practices and emerging issues. Globefish Research Programme, Vol 91, Food and Agriculture Organization of the United Nations, Rome

Gales R (1998) Albatross populations: status and threats. In: Robertson G, Gales R (eds) Albatross biology and conservation. Surrey Beatty and Sons, Chipping Norton, p 20-45

Gales R, Brothers N, Reid T (1998) Seabird mortality in the Japanese tuna longline fishery around Australia, 19881995. Biol Conserv 86:37-56

Gilman E (2001) Integrated management approach to address incidental mortality of seabirds in longline fisheries. Aquat Conserv Mar Freshw Ecosyst 11:391-414

Gilman E (2008) USA Western and Central Pacific Ocean. In: DeYoung C (ed) State of World Marine Capture Fisheries Management - 2006: Pacific Ocean. FAO Fish Tech Pap 488/1. Food and Agriculture Organization of the United Nations, Rome

Gilman E, Freifeld H (2003) Seabird mortality in north Pacific longline fisheries. Endang Spec Update 20:35-46

Gilman E, Lundin C (2008) Minimizing bycatch of sensitive species groups in marine capture fisheries: lessons from commercial tuna fisheries. In: Grafton Q, Hillborn R, Squires D, Tait M, Williams M (eds) Handbook of marine fisheries conservation and management. Oxford University Press, Oxford
Gilman E, Boggs C, Brothers N (2003) Performance assessment of an underwater setting chute to mitigate seabird bycatch in the Hawaii pelagic longline tuna fishery. Ocean Coast Manag 46:985-1010

Gilman E, Brothers N, Kobayashi D (2005) Principles and approaches to abate seabird bycatch in longline fisheries. Fish Fish 6:35-49

Gilman E, Brothers N, Kobayashi D (2007a) Comparison of the efficacy of three seabird bycatch avoidance methods in Hawaii pelagic longline fisheries. Fish Sci 73:208-210

Gilman E, Moth-Poulsen T, Bianchi G (2007b) Review of measures taken by inter-governmental organizations to address problematic sea turtle and seabird interactions in marine capture fisheries. FAO Fish Circ 1025. Food and Agriculture Organization of the United Nations, Rome

Gilman E, Clarke S, Brothers N, Alfaro-Shigueto J and others (2008) Shark interactions in pelagic longline fisheries. Mar Pol 32:1-18

Hastie T, Tibshirani R (1990) Generalized additive models. Monogr Stat Appl Probab 43. Chapman \& Hall, London

$>$ Hyrenbach KD, Forney KA, Dayton PK (2000) Marine protected areas and ocean basin management. Aquat Conserv Mar Freshw Ecosyst 10:437-458

Ihaka R, Gentleman R (1996) R: a language for data analysis and graphics. J Comput Graph Statist 5:299-314

IUCN and Western Pacific Fishery Management Council (2008) Sustainable Tuna Roundtable, 2008 Meeting Report, April 21, 2008, Brussels. International Union for the Conservation of Nature (IUCN), Gland and Western Pacific Regional Fishery Management Council, Honolulu, HI

Johnston RJ, Wessells C, Donath H, Asche F (2001) A contingent choice analysis of ecolabeled seafood: Comparing consumer preferences in the United States and Norway. J Agric Resour Econ 26:20-39

Lewison R, Crowder L (2003) Estimating fishery bycatch and effects on a vulnerable seabird population. Ecol Appl 13:743-753

Majkowski J (2007) Global fishery resources of tuna and tuna-like species. Food and Agriculture Organization of the United Nations, Rome

McCullagh P, Nelder JA (1989) Generalized linear models, 2nd edn. Monogr Stat Appl Prob 37. Chapman \& Hall, London

McNamara B, Torre L, Kaaialii G (1999) Hawaii longline seabird mortality mitigation project. Western Pacific Regional Fishery Management Council, Honolulu, HI

Minami H, Kiyota M (2002) Effect of blue-dyed bait on reduction of incidental take of seabirds. Fisheries Research Agency, Shizuoka

Niel C, Lebreton J (2005) Using demographic invariants to detect overharvested bird populations from incomplete data. Conserv Biol 19:826-835

Sullivan BJ, Brickle P, Reid TA, Bone DG, Middleton DAJ (2006) Mitigation of seabird mortality on factory trawlers: trials of three devices to reduce warp cable strikes. Polar Biol 29:745-753

US Fish and Wildlife Service (2002) Revision of the US Fish and Wildlife Service's November 28, 2000 biological opinion for the effects of the Hawaii-based domestic longline fleet on the short-tailed albatross (Phoebastria albatrus). US Fish and Wildlife Service, Honolulu, HI

US Fish and Wildlife Service (2004) Biological opinion on the effects of the reopened shallow-set sector of the Hawaii-based longline fishery on the short-tailed albatross (Phoebastria albatrus). US Fish and Wildlife Service, Honolulu, HI 
US National Marine Fisheries Service (2005) Fisheries off west coast states and in the western Pacific; pelagic fisheries; additional measures to reduce the incidental catch of seabirds in the Hawaii pelagic longline fishery. Fed Regist 70:75075-75080

US National Marine Fisheries Service (2008) The Hawaiibased longline logbook summary report, OctoberDecember 2007. Data Report DR-08-002, Pacific Islands Fisheries Science Center, National Marine Fisheries Service, Honolulu, HI

US Western Pacific Fishery Management Council (2004)

Editorial responsibility: Rebecca Lewison,

San Diego, California, USA
Additional measures to reduce the incidental catch of seabirds in the Hawaii-based longline fishery. A Regulatory Amendment to the Western Pacific Pelagic Fisheries Management Plan. US Western Pacific Fishery Management Council, Honolulu, HI

Van Fossen L (2007) Annual report on seabird interactions and mitigation efforts in the Hawaii longline fishery for 2006. National Marine Fisheries Service, Pacific Islands Regional Office, Honolulu, HI

Wood S (2006) Generalized additive models: an introduction with R. Chapman \& Hall, London

Submitted: October 19, 2007; Accepted: August 19, 2008

Proofs received from author(s): October 18, 2008 